\title{
Mystery of the Concept: S. I. Taneyev's Choruses, Op. 35, to Words by K. D. Balmont
}

\author{
Galima Lukina \\ State Institute of Art Studies Russian State \\ Specialized Academy of Arts \\ Moscow, Russia \\ E-mail: lukina@sias.ru
}

\begin{abstract}
Op. 35 for male chorus based on Balmont's poetry is probably the most mysterious and little-explored one within Taneyev's artistic heritage. Basing on the analysis of the already published choirs of the cycle and archival drafts the author proposes the original version of the composer's interpretation of the poetry, which stands afar from Taneyev's creative and aesthetic attitudes. The discovered autographs containing previously unknown fragments of the cycle makes it possible to unveil the conceptual height of one of the last works of the great Russian composer and thinker.
\end{abstract}

Keywords-conception; Sergei Taneyev; choral cycle; music based on the poetry by Balmont; op. 35 by Taneyev

\section{INTRODUCTION}

The mystery of op. 35 is concealed in the fact that Taneyev turned to the poetry by Balmont, a most outstanding spokesman of decadent aesthetics which seemed to be foreign to Taneyev's individuality: he preferred the poetry by A. K. Tolstoy, Ya. P. Polonsky or A. S. Khomyakov for his major choral compositions.

For his op. 35 cycle, Taneyev selected the poems from three poetic collections, "Under the Northern Sky" (1894), "In Boundlessness" (1895) and "Silence" (1898). In the books, Balmont pays tribute to "the songs of night and twilight" where "there is so much sick melancholy alongside with the most exuberant flashes" [1], a lot of "weak deadly silence". The amount of poetry read by Taneyev, 233 poems all in all, gives clear evidence of an extremely painstaking and elaborate process of the selection.

Judging by his rough papers, Taneyev began the work in 1911, having plunged into composing his cantata, "At the Reading of a Psalm". A letter of February 11, 1911, sent by the Prague Teachers' Singing Union asking for a musical work as a "gift" for them [2], launched the cycle composition. Taneyev knew the group after his Prague visit, he heard the "Prometheus" chorus sung by them, which became the decisive reason for dedicating the cycle to the society. The full cycle has not survived. L. Z. Korabelnikova managed to find lithographic copies of the choruses from Parts I and III in the archives of the Prague Teachers' Singing Union.
In his letter to A. V. Stanchinsky of June 13, 1912, the composer pointed out, "...I have just finished 11 choruses for male voices (there will be 12 choruses all in all)". It is clear from the letter that Taneyev had originally planned to compose a cycle of three parts. It is supported with his sketchbooks, one of them [3] bearing the original plan of a three-part cycle. By and by, the cycle idea grew to 16 choruses; the order of the poems also changed, which is also proved with archive materials including 1912-13 sketches [4] as well as with publishing the surviving parts [5]. Thus, the idea of Taneyev's cycle on the words by Balmont can be "read out" from those materials.

\section{The PROGRAMME OF TANEYEV'S CYCLE}

Selecting the poems for his cycle Taneyev evidently followed a certain dramaturgic concept. The plotline clearly reveals the dynamics of images, from "sweet sleep" and night reveries through daybreak and red sundown to the silent dream. The closeness of the "silent realm" is emphasized with a poetic "repetition": the text of the $13^{\text {th }}$ chorus as well as of the first one is based on the poem "Silence".

The cycle includes the same landscape motif expressed in different ways: the night skies (the moon and stars) and the water space (the sea, rivers, shores). The first chorus, "Silence", represents a picture with "a pale light of the skies", where "the pale moon crescent" is looking into the waters of a "slumbering river"; the poetic text of the chorus called "The Sea Bed" introduces the landscape where "the sea depths" are dreaming of a free height of the "tender moon". Thus, the cycle plot generates a circle of "dreams", a visionary image of illusive being.

In his cycle, Taneyev expressed the inversive principle characteristic of Balmont's poetry, that of vivid and emotionally semantic "overturn" of contrary phenomena (water-sky, dream-death, darkness-light, day-night, depthheight, silence-sound etc.). Thus, the main theme of "The Sea Bed" chorus (11) from Part III is a mirror image of the first chorus theme, "Silence" (1), see "Fig. 1". That intonational arch makes up the whole that imprints the world reflecting everything everywhere. 




Fig. 1. The initial bars of "The Sea Bed" (11) and "Silence" (1) choruses.

The inversion principle is manifested in particular choruses of the cycle. A significant example is "The Sea Bed" chorus reflecting the contrast of the dark sea bed and moonlight inherent in the poem. The tonal, modal ( $\mathrm{fmoll}-\mathrm{E}$, $F, A d u r)$, tempo and dynamic contrasts between two semantic spheres are evident. However, the composer brings thematism and the texture of the above-mentioned spheres (polyphonic disposition) preserving the outward contrast of the opposites (bottom-top). Thus the image is born, which is reversed semantically. Alongside with the image change there is a remarkable modal clarification in the cadencies of the parts about the sea depths which are "deathly deep" (Cis $d u r$, b. 56) and about the sea bed which is "still lifelessly dark" (Fis dur, b. 101). The final Fis dur chord at the word "dark" prepares the images of beauty praised in the "Sea Song". It is connected with the sea, but not with the sky or the moon.

The system of inward and skyward reflections has a special representation of the main image in the poems of two last choruses of the cycle, that of the swan. In "The White Swan", it embodies the beauty that can be found only between two worlds and two depths: the water ("There is a silent depth below you") and the sky ("There is fathomless air above you"). Such a specific representation of the swan as essentially "pure" and detached from illusive and dual being is emphasized in the poem of the final chorus.

It is important to mention that "The Swan" does not take the final position in Balmont's collection "In Boundlessness": it is the fifteenth of 95 poems. Evidently, the composer noticed its special significance within the whole cycle ${ }^{1}$. The last chorus serves as the epilogue. It presents the image of a dying swan:

...Everything which used to make the life uneasy and delightful,

\section{Everything which used to be love's hope}

Has swept away like a swift dream

And will never go up in flames again.

Comparing of the final poems in Balmont's collections is quite notable. The collection "In Boundlessness" is finished with the poem "Beyond the limits of the limits, to the oceans of lucid boundlessness!" (95), which is followed with "will dash" "to the wonderful world / to the unknown Beauty!" The finals of two other collections are far from the "Swan" poem: "Under the Norther Sky" ends with the poem "Death, lull me asleep" (The life has exhausted me...) (61); "Silence" - "Desert Star" (77).
The white swan's song has joined everything

That bears the seal of the irreparable, as if the bird pleaded his native lake

For mercy.

...He was not singing alive, but dying,

And in his last hour he was singing

Because he could see the truth for the first time,

Face to face with the eternal reconciling death.

The poetic phrase "Could see the truth for the first time" is perceived existentially. The existence initially presented as an ideal is estimated as the irreparable, irretrievable in the face of death; it is the past that "swept away like a swift dream". As a result of the "borderline situation", the real understanding of life essence is revealed, as well as that of one's existence and individuality.

\section{NEW FINDS AND DISCOVERIES}

The surviving Taneyev's autograph of "The Swan" music gives us the opportunity to hear the amazingly penetrant finale of the chorus cycle, with its tragic violin solo. The initial thrilling $a s^{2}$ sound seems to be a heart cry after the four-bar pause, see "Fig. 2".

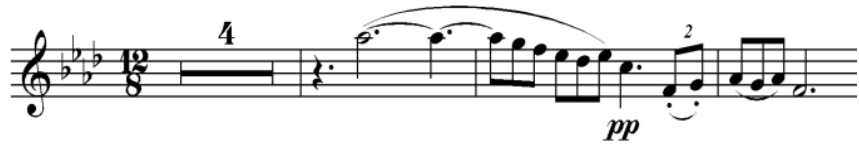

Fig. 2. "The Swan" chorus (16).

In spite of the evident thematic connection of the swan's song theme with the first chorus, "Silence", its conjunct descent and soaring flexible passages lack the initial $A s d u r$ idyllic picture and integrity within the realm of silence, while the intonation structure of the first chorus includes the motif of sweet dreams.

Taneyev could hear its special musicality which can be reached through combinations of rhyming lines (they rhyme in Russian) (silence - reeds; river - clouds; skies - forest; day - shade etc); anaphoric repetitions ("still"; the expression of stillness with such words as "calm", "quiet", "silence", "still" can be found in each stanza); alliterations (t/sh/s "the reeds are sleeping", "sweet dreams", "the moon crescent... is looking down"). The composer could hear all these, and transformed them into echo-like imitations, 
ascending and descending three-chord endings at the rhyming words, in the motif turning round thirds in quiet lulling triple time.

Otherwise, something is not so simple in the intonation structure of the "Silence" chorus. It is not only lulling but also it sounds mysteriously, ambiguously which can be found in the second part at the words "quiet pale light in the skies", "quiet, dark, dreamy forest". There is the initial intonation transformed into something like a salon song with a romantic sixths levitation unexpectedly shipping into an awkward melodic pattern along the sounds of augmented six-four chord resoluted with an affected anticipation. The further sequentive statement (a third above) against tonal deviations towards deep "flattening" makes up a feeling of "impetuosity", "ecstasis" which is out of dreamy character. This subject contradiction gets further development.

In the recapitulation, the "steady" steps of fourths in the main theme played by second basses enter into a "conflict" with the waltz "accompaniment" (tenors and first basses). The contradiction is much more apparent because the musical plan is in semantic "dissonance" with the corresponding poetic lines, "Sweet dreams are breezing in that realm of silence".

By the end of the chorus the poetic text as if dissolves in the music; the intonational movement goes on without any connection with the words' meanings. The independent character of the music is especially perceptible in the sound of the poetic line, "the angels' eyes are looking down". The words here, just like Balmont's ones, do not only carry the meaning, but they also make up a beautiful poetic formula. It is clearly seen in the exaggeratedly impetuous romantic intonation within the register challenging for tenors (number 12), in its repeated sequence developments, in the basses' chromatic intonation spinning in the diminished third ambitus, retracting the chorus finale (numbers 14-15).

In his work, "Simple Words on Symbolic Poetry", Balmont wrote, "...You look, and behind the changeable colours and visible features you see something different, half-revealed beauty, a whole world of hints clear for the heart but almost entirely escaping the opportunity to be expressed in words" [6]. The principle of endless "change of instants", which forms the poetic text basis, defines the corresponding methods of its musical interpretation. The main method of the cycle is circular inversion. This affects the external unity of boundless and bottomless silence dissolving into a gradual transformation of the main images.

Thus, sweet dreams are transformed into an abominable dream, a speechless nightmare in "The Sphinx". The impression of the formidable Sphinx, "a monstrous dream", is created with minimal means: octaval unison, gripping chromatic moves and broad leaps in perfect fifth, tritone, diminished seventh, and utterly high tenor tessiture $\left(f^{2}, g^{2}\right)$.

In the poems of Part 3 ("Dead Ships" (9), "Sounds of the Surf" (10), "The Sea Bed" (11), "Sea Song" (12)), the dream is interpreted as "heartless" and eternal one on the bottom. Such characteristics as "heartlessness" or "lifelessness" reveal the real semantics of the words "dream", "silence", "night", which mean the death.

In the poem "Dead Ships", the image of the ship is presented as "a huge coffin, a floating skeleton", which rushes through "the heartless world of a dreamy desert" and "only the red sunlight / is shining like a funeral torch". The thematism of the "Dead Ships" (9) chorus resembles the rhythmic organization and facture of "The Sphinx" chorus strengthening the intonation unity of the main images, the dream and the death.

It is remarkable that the image of the ship also appears in the poem selected by Taneyev for the chorus of the op. 27 cycle, "On the Boat". V1. Solovyev called that poem by Polonsky "a wonderful sample of a truly poetic allegory" [7], in which the dawn means spiritual light, while the image of the ship in the light of photodossia [8] is like the Noah's Ark, the world salvation stronghold. Balmont's image of the ship is completely asymmetrical — "the lantern of burning life has faded out" there [9].

At first sight, it seems illogical in the intonation process that as the image of dream as death becomes more significant, the motif of movement becomes more emphatic (from a slow "fading shadow" to the ghost ships dashing onward and "the flight ahead"). By Part 4 the sound dynamics increases (from "the quiet forest" with "the leaves' rustle", "grass whisper", "river wave splash" to the "sounds of the sea", waves, roar of the surf, moaning "laughter outbursts", echo rumble and the "threatening appeal of the sea wave"). Such paradox is solved with the fact that the sea element implies death (wave, surf etc.), and that image is developed with attacking crescendo. As a result, the cycle dramaturgy expresses the wild flight to death, while "Sea Song" is perceived as a death hymn, see "Fig. 3".

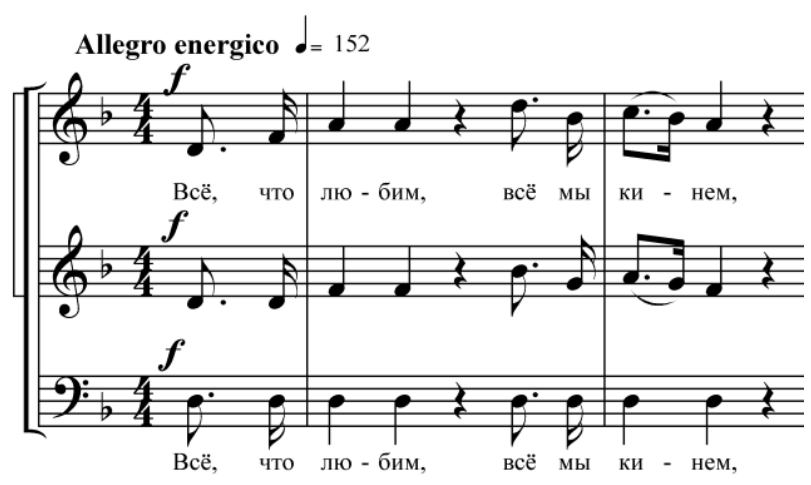

Fig. 3. "Sea Song” chorus (12).

This context clarifies the uselessness of the lyrical hero or any personality within the cycle poetics. In the poems selected by Taneyev, there is no personal pronoun "I", so meaningful in the texts of cantatas and op. 27. Even when the personal pronoun "we" is used (in "Sounds of the Surf" and "Sea Song" choruses), the plurality is impersonal. "We" means the surf and the sea wave. Many verbs in the first person plural make an image of a powerful and active 
destructive force ${ }^{2}$ ("we'll flood", "we'll take", “we'll devour", "we'll climb", "we'll throw", "we speed"). The elemental essence of "we" is revealed in Balmont's text for the chorus "Sea Song". Its plotline is based on a certain Utopian idea of "outraging the vastness", from "we'll abandon everything we love" to "we'll become one with the blue sea, and we'll dream of the wave half asleep on the bottom". Balmont's word is wrapped into the intonation elements unusual for Taneyev, which is very close to revolutionary hymns' melodiousness (even emphatic). The active disposition of the theme is enhanced with a powerful sound of men's voices in two choruses.

The semantic discord of the chorus subject is revealed in the process of the main theme development which loses its initial courage in the very introduction. The image, which is rebellious as such, is distorted and perceived as a comic one.

The "Sea Song" introduction is organized like acceleration: a chain of bouncy motives with a gradually augmenting ambitus together with dynamic development at the words "leads to fabulous aims". Suddenly the movement of "screaming' fanfare motives "stumbles" at gis, in the register which is inconceivably high for tenors at fortissimo. Then a conventional cadence formula as if cuts the expected lengthy final statement. However, as if suddenly recollecting its insufficient persuasive force - a common authentic ending is repeated obtrusively.

The more unexpected is the picture of fabulous world in $F d u r$ part of the chorus. Sensual intonation of oriental coloring prevails in it; it is submerged into viscous imitation and metric tangles of the chorus texture filled with vague triplets imitating the semantics of false romantic dreaminess which does not correspond with heavy sonority of the organpoint in the rhythm resembling the initial revolutionary tune (augmented). Switching from "the balmy weather" to the fanfare panegyric to the "new world of wonders" is similarly unexpected.

In the final $D$ dur part of the chorus, in the counterpoint of the loud calling hymnic theme and the heavy ostinato one (numbers 22-25) at the words "We'll become one with the blue sea...", reckless joy prevails ("we'll sink in the Beauty"). A tiringly long imitation in ritmo ostinato is perceived as an echo of a sort of death ecstasy: "We'll dream of the wave/half asleep/on the bottom".

The ambiguity (almost comic one) of the "Sea Song" chorus is connected with growing contradictions in the intonational structure of the chorus; its dynamics reveals the fictitious "fabulous" objectives. The phenomenon of the comic expressed in the musical interpretation of Balmont's poetry reflects its irony towards such wild "musical delights" aimed at ecstatic "removing and abolishing of personal consciousness aspects" [10]. That unconscious "madness" of Dionysian cult was foreign to Taneyev's creative credo.

To understand the difference of op. 27 and 35 it is significant to compare them with the poems by Polonsky where the pronoun "we" is used with the verbs of positive activities: "We'll fix the masts, we'll tighten the sails, / We'll go and roar (a song/) in unison: "Lord bless the coming day!"”.
According to aberration law, the poetics of "Silence" chosen for the chorus following "Sea Song" is now perceived as a full inversion of the first chorus: according to the poetics of Dionysian ecstasy, the tranquility of "Silence \# 2 " is "the deceptive and abominable stillness of the pool where hidden whirlpool is swirling" [11]. This is Balmont's definition of quiet and silence in a poem by Baudelaire. The world of Balmont's cycle is perceived similarly. Judging by the autograph of the chorus initial theme [12], the image of diabolical silence has determined its scherzo character.

The chorus after "The Wreck" poem finishes the "iridescent thread" of dreams and vague ambitions". The collision of emotionally contrasting images makes a picture of the dying "realm of silence" which is similar to the enchanted garden surrounded in the "scent of storm" and the desire "to embrace and join" the thunderstorm. A complex of changeable, "instant", contradictory psychological states of mind establishes the wreck of idyllic peace. Judging by the chorus draft, Taneyev preserved that poetic image, which is seen in $g$ moll key intonation based on a swift spin of the tertian motive in counterpoint with moaning seconds.

The stylistics of the extant op. 35 choruses is different from both op. 27 cycle, and the rest of the chorus compositions. We agree with L. Z. Korabelnikova who mentioned a tendency towards "reticence, even austerity of stylistic devices ... In the eight choruses we know (there is no reason to think differently about others) there aren't any elaborate polyphonic methods or forms" [13]. In addition, the counterpoint preferred by Taneyev and used as the linking element of the musical texture, acquires an absolutely contrasting function. Isolated and secluded contrapuntal combinations seem to be schematic transpositions of voices in some choruses. Thus, the intonation movement becomes discontinuous, unnatural and far-fetched.

Such kind of "movement play" is characteristic of the "Visions" chorus. In its second part, the contrapuntal transpositions contribute to literal illustrations of the words in the chorus texture, now expanding, now compressing (in the reverse and indirect voice movements).

Such examples of flexible counterpoint creating seeming dynamics can be seen in the choruses of "Dawn" (4) and "The Sea Bed" (11). Besides intentional impoverishment of processual nature of the complex counterpoint, a notable feature of the cycle is sequencing tending to inertness, to "free" movement to nowhere, to nothing. Progressions and "Screscending" repetitions in the choruses of Balmont cycle result in "swelling" sound which is suddenly interrupted with either common cadencing forms ("Visions", bb. 12-13, 6263, 76-78, 96-98, 116-118; "Dawn", bb. 39-40; "The Sphinx", bb. 11-13, 30-31, 48-49; "Sounds of the Surf", bb. 31, 68, 72-73; "Sea Song”, bb. 19-20, 79-81, 82-83, 114$115)$, or with interrupted cadencies and various kinds of keynote retraction ("The Sphinx", number 7). Intonation "deceit", or "substitution" appears - the resolution is either ahead of time as if "breaking off" the anticipation of the keynote, or in contrast, it intentionally moves its emergence away. Both produce a comic effect. Very often the intonation logic sort of leads nowhere: the movement "bumps" into the 
same repetitive circles, which adds a character of constraint to the musical development; it includes the conscience hypnotized with idée fixe ("Visions", "The Sphinx", "Sea Song"). This way, the effect of "worthless spin" [14] reflecting the idea of evil infinity is produced on the intonation level.

Before the epilogue, the choruses transmit the principle characteristic of Balmont, that of "instants" change", uncertainty of states, establishing the fictitious but alluring "ideal" of the silence realm. Denying the sympathy with him lead Taneyev to a special form of comic approach to the meaningful analysis of poetic words. That approach is close to Socrates irony with its idea of promoting search of truth. Like great men of wisdom, Taneyev directs our minds (internal eyes) to the supersensible layer of the Divine world, as if he echoed the preaching of Theophan the Recluse: "First of all, uncover the eyes of your mind not to keep it blind" [15]. That address to inner man is the obvious reason of "The Swan" poem to have been chosen for the final chorus. As we can judge by the surviving fragments, it lacks comic reflexion. The dying swan's song does not fit into the illusive reality dominating in the poetics of all the other choruses of the cycle. There is a "gulf" between the bright and vivid elegiac melody played by the solo violin (see Ill. 2) and the initial intonation of the first chorus, "Silence" derived from it. The conceptual apartness of the violin finale is strengthened with the instrumental solo compared to male chorus and with lack of words, which gives the opportunity to express "the last breath of the soul" with "clear means", and with high register of the violin melody.

The tragic feeling heard in the melody as if "tears" the web of "endless, bright and carefree dreaming" [16]. Here are no depressive dissonances in it, or desperate intonations. The discovery of essentially real (not illusive or visionary) world determines the tone of the melody. It sounds elevated evoking the feeling of inexpressible mystery and implying the cathartic meaning of the epilogue, the soul awakening from the captivity of "the deadly weak silence" [17] and the pain of personal imperfection.

The "farewell" statement of the violin solo in the very end is interrupted with the long tied $c$ sound played pianissimo; it seems to be dissolving and stops being appearing, see "Fig. 4".

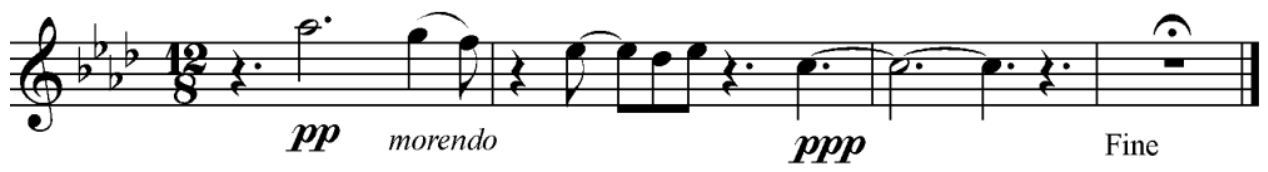

Fig. 4. The final bars of the solo violin theme from "The Swan" chorus (16)

Contrary to the descending movement of the melody, it does not render the fall or death. The outworldly quiet dynamics, and the grading of clear metrics with the help of pausing at a strong beat, the motives of heart breath as if about something unspeakable, the As dur enlightenment and finally, the theme ending with a fermata pause taking a whole bar - all these make up the effect of fading and saving hearty determination to reach the Heaven.

\section{CONCLUSION}

According to A. Akhmatova words, “.... reciting poet adopts the poetry recited, but not as it is generally accepted; he adopts it with a new poem" [18]. Undoubtedly, Taneyev saw Balmont's poetry as a chance to realise his artistic idea, far from the decadent cult of "melancholy, depression and twilight", and of "the force of inner inevitability" [19]. The ontological "turn" from the darkness of unreason to the light of the Truth expressed in the cycle programme, tells us that Taneyev's intention towards Balmont's poetry chosen for the op. 35 choruses is close to the composer's big works. Indeed, the idea of the cantatas, "John of Damascus" and "At the Reading of a Psalm", the op. 27 choruses to words by Ya. P. Polonsky, and "Oresteia" trilogy is associated with enlightenment, transformation, and with the idea of spiritual ascent to the Empyrean ${ }^{3}$. The principal difference is that the

A paradox it might be, but the idea of "Oresteia" trilogy, after the ancient Greek tragedy by Aeschylus, is similar to the choruses. Taneyev (together with V. Venkstern) introduces the evangelic understanding of sin, cycle programme does not have a single word of forgiving brotherly Christian love, the universal principle and mode of being. Moreover, the "Sea Song" is about "non-love" ("we'll abandon everything we love"). It is a paradox, but in the original cycle variant (1912) the chorus of the same title was the first one. Accordingly, the opus dramaturgy was quite different then - from "non-love" as a destructive Dionysian element to the death ("The Sea Bed"). However, such a finale was evidently unacceptable for Taneyev the creator who claimed that art is a "spiritual activity ... that united people with love, not with violence, which implies the joy of uniting, or suffering caused by separation" [20]. The elevated idea was provided with the image of "Swan" which is perceived as a symbol of the soul awakening from the dream of "the collective conscience tempted with reveries of the happy "nowhere", fabulous Utopian happiness" [21] without love.

In Balmont's "swan song", Taneyev heard the prophecy of the poet's own future [22] and many other people representing the intellectuals of the late 19th-20th centuries who called to pushing "destructive and reviving worldview" with Dionysian hymns in their "orgiastic madness" which "shakes the whole world smiling" (F. Sologub) and in their "feeling of wonderful power and abundance of strength, understanding of impersonal and weak-willed unruliness, and terrifying and delightful loss of one's individuality within the chaos" (Vyach. Ivanov).

temptation and conscience into the Greek tragedy. Orestes goes the way of Holy Passion towards repentance. 
The surviving "pages" of op. 35 give us the opportunity to hear not only the thinking composer warning his contemporaries of the forthcoming social and cultural disasters, but also the call-out appealing to us, the future generations, calling to spiritual revival...

\section{REFERENCES}

[1] Balmont K. D. Simple words on symbolic poetry // Balmont K. Songs of hundred sounds. Yaroslavl. Upper Volga Pubishers, 1990. P. 265.

[2] The quoted letter is kept in the archives of Taneyev fonds of P. I. Tchaikovsky Preserve Museum (STPM). See: $\mathrm{B}^{11}$, No 1480.

[3] State Central Museum of Musical Culture (SCMMC), f. 85, No 315.

[4] STPM, B ${ }^{1}$, No 226-234, 240.

[5] Taneyev S. Choruses a cappella. In two books. Iss. 2. M.: "Muzyka", 1991. P. 116-182.

[6] Balmont K. D. Op. cit. P. 265.

[7] Solovyev V. S. Literary Criticism. M.: Sovremennik, 1990. P. 162.

[8] Photodossia means donation of light (the term by Pseudo-Dionysius).

[9] Balmont K. D. "Dead Ships".

[10] Ivanov V. The Native and the Universal. M.: 1994. P. 92.

[11] Balmont K. D. Preface // Baudlaire's Poems. Moscow: Petrovskaya biblioteka, 1895. P. V-VI.

[12] : STPM, $B^{1}$ file No XXI No 234. Themes for choruses op. 35. IV.

[13] Korabelnikova L. Z. S. I. Taneyev's creative activity. M.: Muzyka, 1986. P. 218

[14] Hansen-Loewe A. Russian symbolism. The system of poetic motives. Early symbolism. SPb.: Akademichesky proekt, 1999. P. 117

[15] Sotnitsa ABC Book. Fundamentals of percepting the divine and the humane. M.: Sibirskaya Blagozvonnitsa, 2002. P. 41.

[16] Balmont K. D. "Half-and-Half".

[17] Balmont K. D. "The Swamp".

[18] Naiman A. Tales of A. Akhmatova // Novy Mir. 1989. No 2. P. $98-$ 131. P. 120.

[19] Balmont himself characterized his poetry of his early collections in such a way. See: Balmont K. D. Songs of hundred sounds: selected works (poetry and prose).

[20] Taneyev S. I. Various extracts and notes on philosophy. Cit. ex Lukina G. U. S. I. Taneyev's works in relation with the Russian spiritual tradition. M.: Kompozitor, 2015. P. 208.

[21] Ilyin I. A. I am peering into life. A Book of Thoughts // Ilyin I. A. Complete Works in ten volumes. Vol.3, Moscow: Russkaya kniga, 1994.

[22] Zaitsev B. K. The faraway. Washington: Interlanguage Literary Associates, 1965. P. 38-47. 